\title{
THE RISE OF COMMERCIAL MEDIATION IN AUSTRALIA- REFLECTIONS AND THE CHALLENGES AHEAD
}

\section{Greg Rooney}

\section{Abstract}

The last 25 years has seen a growth in the use of mediation in the civil and commercial jurisdictions of the states and territories in Australia. There is now a robust mediation market with "virtually no civil case going to trial without at least one round of mediation" This paper will chart the rise of commercial mediation in Australia over the last 25 years.

It will also reflect on a number of issues that have underpinned this growth including why mediation works, the source of the mediator's power and why people get trapped in conflict.

It will examine the emerging collaborative economy particularly the direct link between risktaking and innovation, essential for maintaining the increasingly short time at the top in the 21 st Century economy.

It is through the ability of management and external advisors, including lawyers, to creatively manage the tension created by risk-taking that best fosters a culture of trust and innovation.

If lawyers do not adjust their adversarial culture and develop the soft skills necessary to meet these challenges organisations will find people with degrees in dispute resolution, business, commerce, psychology and engineering that will.

\section{Keywords}

Commercial mediation, Australia, private mediator, NADRAC

\section{Overview}

The last 25 years has seen a growth in the use of mediation in the civil and commercial jurisdictions of the states and territories in Australia. There is now a robust mediation market with "virtually no civil case going to trial without at least one round of mediation" (Annual Report of the Supreme Court of Victoria, 2009 -2010: 46). There has been a corresponding fall in the number of matters going to trial in the commercial courts. This has occurred despite some passive and at times active resistance from the 
legal profession and the judiciary.

This paper will examine the rise of mediation in Australia and the challenges it has brought to the legal profession and the adversarial litigation processes. It will also suggest lessons for the relatively young profession of mediation.

There is no one single reason why this change has occurred. Several factors have been in play, the foremost of which is that mediation, whether voluntary or compulsory, seems to work. When people spend sufficient time together the motivation to settle can overcome even the most stubborn parties. So the mediation product, when used, is an effective method of resolving conflict.

The main drivers of this growth in mediation have, however, come from the changes within civil society and commercial culture as we have moved into the more complex $21^{\text {st }}$ century environment. The $20^{\text {th }}$-century Western commercial model of top-down fixed black letter contracts enforcing risk transference has been challenged by the far more complex reality of the current interconnected commercial space. The principal drivers of this new reality are the need to sustain commercial and individual relationships, embracing a sustainable balance between risk and reward, seeing conflict as an opportunity for change and valuing the importance of soft management skills to bring everything together.

Evidence for this change can be seen in the exponential rise of the collaborative economy built on reduced transaction costs and in-house on the spot conflict resolution with the aim of eliminating transactional cost particularly legal and regulatory costs and the litigation model for resolving disputes.

The legal profession has contributed to this change by effectively pricing itself out of the market at the very time the commercial value of its adversarial/judicial dispute resolution model is being challenged.

The mediation product is also being put under pressure by these factors. It has been dominated by retired judge / senior counsel mediators practising almost exclusively late term mediation using door of the court style shuttle negotiation. It tends to be directive, evaluative and solution focused. It suits the legal profession because it is markedly similar to the adversarial litigation process. By being late term it also preserves the profession's ability to harvest maximum legal fees.

There will always be a need for some late term mediation but early term mediation provides an opportunity for the legal profession to connect with the new economy particularly by engaging actively with the parties in the very early pre- litigation phases of disputes.

Working with parties at the very beginning of their conflict will require a far more nuanced approach and style from mediators particularly the ability to work with parties in the here and now of a joint session. It will also require the ability, especially for lawyer mediators, to become comfortable with the parties' emotional state and their interpersonal relationship issues. This is because the decision to say yes or no to a deal is made at an emotional level rather than at an intellectual level. It is therefore important that mediators connect with the parties at this level very early in the litigation cycle particularly through engaging with them and their attorneys in early pre-mediation meetings. 
This will require mediators to move beyond hard negotiating techniques to access soft skills. Soft skills include the ability to remain present in the moment, intuition, empathy, rapport, managing the challenge of being an irritant and the use of time and space (Temporality, 'The Third', 'The Field') and Meditation/Mindfulness (Rooney and Ross 2012).

This paper will chart the rise of commercial mediation in Australia over the last 25 years as well as focusing on the lessons learned and challenges ahead for the mediation profession, the courts and judiciary, legislature and legal practitioners.

It will also examine two issues. Firstly, why does mediation work and, allied to this question, what is the source of the mediator's power and influence over the parties and their lawyers in the session? Secondly, why do people get trapped in conflict and are unable to negotiate their way out? It is through understanding these two issues that mediation can find its proper place, working alongside the courts and the legislature to foster economic prosperity through the creative resolution of conflict.

\section{The Australian Experience 1990 to Date}

There have been a number of significant contributors to the development of commercial mediation in Australia.

\section{The Rise of the Private Mediator}

The first major initiative involving mediation and the courts took place between 1991 and 1993 when the Law Societies of the states of Queensland, New South Wales and Victoria partnered with their respective superior commercial courts to conduct what the first two states called Settlement Week and Victoria called the Spring Offensive. Lawyers who had undertaken mediation training were brought together for an induction workshop and were then allocated mediations referred directly by the judiciary from the list of long-running cases.

It is of significance that it was the judiciary and the legal profession, not the legislature that embraced this new process of mediation as a way of dealing with the huge backlog of cases that had built up. It heralded the start of the private mediation movement in Australia especially for lawyer mediators. It provided an opportunity for a significant number of lawyers to obtain practical mediation experience both as mediators and as lawyers acting for the parties in those mediations.

Many of the lawyers who started their mediation careers in those settlement weeks in the early 1990s went on to fill the roles of mediators in a number of substantive mediation panels set up by the legislature in various industries. These included panels for farm debt mediation, franchising mediation, horticultural mediation, retail leases mediation and a host of other schemes.

There is now an active market for private based lawyer mediators in Australia. Over the last 25 years a body of very experienced lawyer mediators has emerged in all states of Australia which the legal profession can call on to mediate often quite complex commercial matters. 


\section{The Sir Laurence Street Effect}

A powerful influence on the development of a private legal-based mediation profession was the former chief Justice of the New South Wales Supreme Court Sir Laurence Street. He retired from the bench in 1988 and commenced a very lucrative and successful mediation practice. He was held in high esteem both as a jurist and as a mediator by the broader legal profession, commerce and industry as well as politicians on all sides. He gave the emerging profession of mediation legitimacy within the eyes of the judiciary and the legal profession and helped to overcome the initial scepticism at this new profession. $\mathrm{He}$ completed more than 2500 mediations in a wide variety of jurisdictions up until his recent retirement.

More importantly he had the ability to communicate with people and lawyers and was able to use a broad process that combined a facilitative and a subtly directive mediation style. He was a very effective and creative mediator who, through equal measures of charm and guile, was able to build a constructive relationship with parties as well as with their lawyers.

Unlike many of the latter day judicial and senior lawyer converts to mediation he was not afraid of directly engaging with the parties in the joint session. In fact, he embraced it is a powerful tool for helping resolve some of the more difficult and complex commercial disputes such as the Spedley mediation (Slattery Q.C. 1993).

\section{NADRAC}

Another significant development was the initiative by the Federal Attorney General to appoint a panel of experienced mediators from both the lawyer and non-lawyer sectors to advise on policy issues with respect to alternative dispute resolution within a legislative framework. The committee's title was the National Alternative Dispute Resolution Advisory Committee (NADRAC). This gave experienced mediators direct access to policymakers and politicians at a time when there was much ignorance and misinformation in the general community on the positives and negatives of mediation. It allowed some practical realism to be brought into the discussions with respect to proposed legislation.

NADRAC made two long-term contributions to the growth of mediation in Australia. The first was that it developed, in consultation with the broad legal and non-legal mediation community, an Australia wide set of national mediation standards and accreditation (NMAS). Although NADRAC adopted a minimalist approach the standards have had the effect of forcing a number of sitting and retired judges and senior lawyers to undertake basic mediation training. These standards have challenged, and continue to challenge, the illusion held by a significant number of judges and lawyers that they were natural mediators simply because of their legal training and experience.

NADRAC's second significant contribution, which was a focus on pre-action litigation requirements, was its 2009 report titled "The Resolve to Resolve: Embracing ADR to Improve Access to Justice in the Federal jurisdiction". This, together with an internal report within the Federal Attorney General's Department, led to the enactment of the Federal Civil Dispute Resolution Act 2011(Cth) and has had an influence on similar legislation in Victoria, New South Wales and the other states. 


\section{Australian Judicial Mediation}

There had been pilot programs in the late 1980s for court annexed mediation in a number of courts particularly the Federal Court of Australia and the New South Wales Land and Environment court. However, they evolved more as court Registrar lead ADR processes with occasional participation by judges.

There has been continuing debate within Australia as to whether the judicial role should be kept separate from the mediation role. A number of judges including Sir Laurence Street and the former Chief Justice of the Supreme Court of Queensland the Hon. Paul De Jersey advocated that the two roles be kept separate. As a result, most State based commercial courts have been more practitioner lead with respect to ADR processes.

While some judges in a number of jurisdictions will make themselves available for a mediation role within their own courts the majority are happy to refer to private mediation practitioners. Most mediation when conducted within the various court systems are more in the form of pre-trial conferences and more often than not conducted by court officers such as Registrars and Masters.

There has been some reluctance amongst Federal Court judges to act as mediators. Although the provision for judicial mediation remains in force under the Federal Court Rules it is utilised extremely rarely (Justice P. A. Bergin 2007).

The problem with judicial mediation generally is that mediators need an effective judicial system to work off against. The formal Justice system needs to be a potent threat to the parties should they fail to settle. If the judicial process becomes just another quasi-ADR process, then that threat is effectively diminished. Mediation and the formal judicial processes need to properly balance eachother.

Pre-litigation mediation has the most direct effect on reducing the cost of justice well beyond that of late term judicial mediation. For the legal profession, especially lawyer mediators, there is an obvious conflict of interest. It is not financially in the interests of the legal profession to actively take steps to reduce the cost of Justice. Yet this is what early mediation is attempting to do. To counter this threat, the legal profession has developed a comfort with late term mediation because it ensures that the legal costs of bringing a matter to fruition will not be jeopardised by an unfortunate early settlement.

\section{Early Australian Legislated Intervention}

The initial interventions by the legislature began in the early 1990s more as a response to debates about whether the courts had the power to order non- consensual pre-litigation mediation. This issue partly arose out of the settlement week and spring offensive initiatives. Some judges were prepared to find that they had that power within their inherent power to manage their own court. Some novel approaches developed including setting matters down for hearing in a priority list if the parties had attempted mediation and in a non-priority list if they had not.

By the end of the 1990s most states had introduced legislation to give courts the power to order non-consensual mediation. Some courts actively applied those powers particularly in Queensland during 
the tenure of Chief Justice De Jersey who championed a practitioner lead mediation approach. Other state courts were less proactive while others simply ignored their powers. It was often at the level of the individual judge to decide how proactive they were in" encouraging" and later directing parties to mediation.

By the mid-1990s the legislature began to take a more proactive and directive role in promoting mediation within specific jurisdictions and industries. A host of legislation was introduced mandating compulsory ADR processes for farm debt, franchising, residential tenancies, retail tenancies, small business, building disputes and strata schemes management, the various state based workers' compensation mediation panels, common law work injury claims, and administrative law tribunals in the various states and territories of Australia.

These legislated initiatives have been referred to as 'scheme' arrangements (Sourdin March 2012) and are generally government funded whether through a private mediation organisation such as "The Office of the Mediation Adviser" for franchising disputes or run through government departments such as the New South Wales Department of State and Regional Development for retailtenancies.

Perhaps the most dramatic scheme was that introduced by the New South Wales legislature to abolish the long established Workers Compensation Court. It was replaced by the Workers Compensation Commission using a Med/Arb process. A notable feature was the deliberate appointment of experienced mediators as the arbitrators over that of the experienced members of the adversarial Workers Compensation Bar. The adversarial culture changed immediately because of the cultural alignment between the Med/Arb process and practising mediators acting as the arbitrators. It is a fate that has hung over the Family Court of Australia for a number of years because of the continued attachment by the family law judiciary to traditional adversarial processes despite having the most comprehensive pro ADR legislation and rules in Australia. This is an example of how legislation, by itself, cannot facilitate cultural change without genuine cooperation from the judiciary.

\section{Legislating Pre-Action Requirements in the Superior Australian Commercial Courts}

By the mid-to late 2000's the legislature in the various states and territories started to introduce civil pre-action requirements. At first they were limited to general pre-action steps such as requiring lawyers to advise their clients of the availability of ADR processes and for parties to exchange written offers and responses within set time-frames, disclose documents and minimise delay. There also started to emerge rules to introduce behavioural expectations for lawyers including the duty to act in a reasonable manner, cooperate, to act honestly and in New South Wales the introduction of the concept of "good faith" (Supreme Court Civil Rules 2006 (SA) r33, the Supreme Court (General Civil Procedure) Rules 2005 (Vic) and the Courts and Crimes Legislation Further Amendment Act (NSW)2010).

The judiciary and the legal profession seemed to generally accept these directions from the legislature principally because they were left free to self-regulate their behaviour. The oversight of their behaviour is left to the individual judge. Lawyers are experts at analysing the foibles of individual judges and can moderate their pre-litigation behaviour accordingly. However, organised resistance started to 
develop when the legislature went one step further in seeking to impose certification obligations on parties and their lawyers requiring them to confirm that they have complied with the relevant pre- action obligations.

The Federal Government, the New South Wales and Victorian governments introduced Acts of Parliament requiring forms of certification of pre-action requirements. The Federal government introduced the Civil Dispute Resolution Act of 2011(Cth) which remains in operation. However, both New South Wales and Victoria's similar pre-action legislations were repealed when both states had a change of government.

\section{The Federal Civil Dispute Resolution Act 2011 (Cth)}

The key feature of the Federal legislation was that it introduced a form of certification where the disputants had to file a genuine step statement before commencing action in a range of civil disputes within the Federal jurisdiction.

The relevant rules of the court have restricted the 'genuine step statement' to a maximum of 2 pages. The relevant sections of the Act are as follows:

\section{$\underline{\text { Section } 3 \text { Object of Act }}$}

The object of this Act is to ensure that, as far as possible, people take genuine steps to resolve disputes before certain civil proceedings are instituted.

\section{Section 4. Genuine steps to resolve a dispute}

(1A) For the purposes of this Act, a person takes genuine steps to resolve a dispute if the steps taken by the person in relation to the dispute constitute a sincere and genuine attempt to resolve the dispute, having regard to the person's circumstances and the nature and circumstances of the dispute.

(1) Examples of steps that could be taken by a person as part of taking genuine steps to resolve a dispute with another person, include the following:

(a) notifying the other person of the issues that are, or may be, in dispute, and offering to discuss them, with a view to resolving the dispute;

(b) responding appropriately to any such notification;

(c) providing relevant information and documents to the other person to enable the other person to understand the issues involved and how the dispute might be resolved;

(d) considering whether the dispute could be resolved by a process facilitated by another person, including an alternative dispute resolution process;

(e) if such a process is agreed to:

- agreeing on a particular person to facilitate the process; and

- $\quad$ attending the process;

(f) if such a process is conducted but does not result in resolution of the dispute- considering a different 
process;

(g) attempting to negotiate with the other person, with a view to resolving some or all the issues in dispute, or authorising a representative to do so. The Federal Civil Dispute Resolution Act 2011 (Cth)

The Federal Attorney General is currently reviewing the operation and effect of this legislation which hopefully will provide some statistical evidence to better inform the debate.

There is limited case law on what constitutes reasonable behaviour with respect to pre-litigation obligations. The courts have tended to explore what constitutes unreasonable or not genuine behaviour by the parties and their lawyers. The limited case law to date has set a low bar in that the accepted standard of behaviour appears to be whether there is any evidence of pre-litigation contact between the parties or their lawyers. (Sourdin November 2012: 910)

\section{The New South Wales and Victorian Legislative Experience. One Step Forward and Two Steps Back.}

It is of interest to examine why both New South Wales and Victoria took a step back from the Federal legislation when both governments changed to a more conservative party. The arguments for this have exposed the fault lines that have developed over the years between the mediation process and the legal profession/judiciary.

The New South Wales government simply postponed the previous government's legislation and then repealed it. In the second reading speech the Attorney General noted that it was necessary to gather more evidence about the impact of the Federal reforms and that an evaluation of those reforms was being undertaken by the Federal Government. This report is still pending.

The new Victorian Government's response was more direct and reflective of the concerns from sections of the legal profession and the judiciary. In his second reading speech repealing the legislation the new Attorney General stated:

However, the government's view and the view of many practitioners, is that to seek to compel parties to do so through these heavy-handed provisions will simply add to the complexity, expense and delay of bringing legal proceedings, because of the need to comply with these mandatory requirements, whether or not they are likely to be useful in any particular case.

In many cases these pre-litigation requirements will allow dishonest parties to postpone and frustrate proceedings. Sourdin, October 2012, 307.

The twin arguments that there is not enough evidence and that the process will do more harm than good (without similar evidence) seem to represent the more conservative elements of the legal profession/ judiciary's resistance to directive pre-action requirements.

Perhaps the certification requirement is seen as being just one step too far for the profession and the judiciary that has become ever more wary of the expanding use of mediation. Nevertheless, the latitude and freedom allowed through, at times, minimal supervision by the judiciary might be coming to 
an end. There is the implication, by this suite of legislation, that the legislature views the profession as not taking seriously its pre-action requirements and that total self-regulation may no longer be warranted. It is clear that the advance of mediation over the last 25 years has resulted in a reduction in court time in many jurisdictions with the associated loss of status particular for the judiciary. There have also been financial implications for practitioners.

\section{Lessons Drawn from the Australian Experience Market Forces}

The growth of mediation in Australia is partly due to the effect of market forces at play. It started with the early growth of the private lawyer mediator and the substantial financial rewards that flowed especially for Senior Counsel and retired Judges. It has become an attractive adjunct to standard legal practice. The professional ability of the earlier pioneers, including Sir Laurence Street, to include a facilitative aspect to their mediation process established a high standard of professionalism. This more than anything else gave mediation its initial legitimacy as a real alternative to adversarial litigation.

There has also been a societal change in Australia, especially in the commercial context. It is more than just the corporate world trying to reduce costs. There has been a fundamental shift towards a more collaborative management style within corporations and the rise, especially recently, of the "collaborative economy" as evidenced by the Uber ride-sharing and Airbnb accommodation platforms.

This has been aided by the development of model litigant obligations that governments have imposed on government departments as well as many private commercial institutions such as insurance companies taking more pro-active steps to resolve disputes earlier.

There is also an increasing trend for private mediations to take place at a much earlier date often immediately after a letter of demand has been issued. This can partly be put down to pre-litigation ADR legislated initiatives and the growing awareness and acceptance of mediation within the commercial community.

Often these earlier mediations are conducted by solicitors rather than by legal counsel drawn from the private bar. It might be partly a cost saving exercise but solicitors often have a deeper long-term personal relationship with their clients which can be useful in helping to bring in some business reality and commercial sense to the offers of compromise especially at the earlier stages of the dispute. However, they still tend to be evaluative and solution focused.

\section{The Power of Mediation - Why Does Mediation Work?}

The principal lesson from the Australian experience is that mediation, as a process, has a power and momentum of its own. It has continued to grow despite the passive (and sometimes active) resistance of the legal profession and the judiciary. It would not have survived and continued to evolve over the last 25 years otherwise.

Why does mediation work? It is assumed by many mediators, particularly ex-judges and senior counsel that the power and driving force of the mediation process resides in the mediator. While the 
mediator has an important role, in my view, he or she does not constitute the core power behind the success of mediation as a process.

Does the power of mediation reside in the expertise, knowledge and skill of lawyers representing the parties in the mediation and their relationship with their client's ability to compromise? In my view this does not constitute the core of what is mediation.

I have come to the view that what is at the core of mediation and why it works so well is the simple fact that it is a venue. A venue where the parties are required to set aside time to spend with their lawyer, the other party and that party's lawyer in the company of a mediator. The venue, like the door of the court, requires lawyers to look at their file in a holistic manner rather than piece by piece actioning over a long period of time. It is where the parties are presented with the tantalising option that the matter could resolve that day if they so choose.

This concept can be best described by the following quote from Michael Slattery QC recalling his first experience as a lawyer acting for a party in a large commercial mediation conducted by Sir Laurence Street: -

The fatal step in mediation is to say yes to the idea in the first place. Mere participation in the process works insidiously over time to suspend, then overcome, much of the detachment of lawyers and the cynicism of their clients. Once hours, days or even months have been spent mediating in a structured environment, human reactions attempt to give all this activity some purpose. The motivation to settle then appears. (Slattery 1973, 23)

Mediation is more than the sum of the parts of the people who are present. It is a collective enterprise where the mediators, lawyers and the parties individually and collectively play a role. Each participant certainly has an influence both positive and negative, but they do not individually make the process. The structure and environment of the venue creates something that emerges out of this group activity that has an existence of its own, almost like a separate person, and is capable of thinking in ways as a collective that neither the mediator, the lawyers or the parties as individuals are capable of generating on their own (Rooney and Ross 2012). Psychoanalysts call it intersubjectivity or 'The Third’ (Ogden 2015, 290).

The belief that the person of the mediator constitutes the core of the mediation process is, in my view, the principal reason why mediation is misunderstood as a process by many in the law, the judiciary and policymakers.

\section{The Source of the Mediator's Power}

Theorists point to at least 5 models of mediation being the settlement model, the facilitative model, the therapeutic model, the transformative model and the evaluative model. However, from a practice point of view there are only two models; the model that utilises the joint session and the model that does not use the joint session.

Sir Laurence Street and other earlier pioneers' use of the joint session model has of late been 
challenged by the more recent converts to mediation. They appear to be more comfortable with the no joint session model preferring to sits as a quasi- judge hearing submissions from the party's lawyers without any real or direct contribution from the parties.

The latter approach has contributed to the view, especially with the more adversarial lawyer mediators, that the power of the mediator comes directly from their expertise in the relevant area of law, their status as a senior lawyer or retired judge and their ability to "persuade" parties to settle. This translates into a process that is directive, evaluative and solution focused. The legal profession is comfortable with this approach because it has a marked similarity to the adversarial litigation process. Lawyers feel culturally at home. Implied in this is the belief that a successful mediation is due to the ability and capacity of the mediator.

I would argue the opposite is the case. The vast majority of the more than 1,500 mediations I have dealt with over the last 24 years have settled. I did not settle any one of those cases. They settled themselves. My contribution was to clear the path for the settlement and in effect to try to stop them from not settling. There might have been one or two cases that I did a 'brilliant' intervention but more often than not I just cleared the way, particularly helping the lawyers get out of the way and avoid tripping up their own client, the other party and the other party's lawyer. As lawyers have become more familiar with the process I have found them to be of great assistance not only to myself as the mediator but to their own clients and the ultimate outcome.

I would argue that there is a general misunderstanding of the power of the mediator. In my view the power of the mediator comes from having absolutely no power. It is a paradox in that having no power allows the mediator entry into the relationship plane that exists between the parties which is at the core of the decision to hold fast to a position or whether or not to compromise. While mediation takes place in the shadow of the law it is at the level of the relationship plane that the mediator has the most effect. That is why Sir Laurence Street's personal charm with the parties was so effective.

This challenges the concept of mediator neutrality because the mediator is, in a sense, manipulating the parties at an emotional level. This places far more power and responsibility in the hands of the mediator and requires a higher degree of personal ethics and self-awareness on their part (Rooney 2015).

\section{Why Parties Get Trapped in Conflict - Triggering the Nash Trap}

What draws people into conflict and keeps them in ever deepening cycles of claim and counter claim? Why do they end up being trapped in the litigation process? The answer to this question can be found in game theory. U.S mathematician John Nash (the movie 'The Beautiful Mind') postulated that Adam Smith's declaration that 'In competition, individual ambition serves the common good' was incomplete. Instead the best result is for everyone in the group doing what's best for himself AND the group. This became known as the Nash Equilibrium and won him a share of the Nobel Prize for Economic Sciences.

Nash used advanced logic and mathematics to examine situations in which parties in competition 
reject a strategy of co-operation that would benefit everyone and instead act independently in an attempt to maximise their own self-interest. They quickly fall into a trap because if one party refuses to compromise it is not worth the other party giving way.

Nash postulated that a point of balance is quickly reached in which either side cannot independently escape without suffering a loss. He called this trap the Nash Equilibrium which he postulated was lying in wait for every situation of competition and conflict in which parties are unwilling or unable to communicate.

Cooperation would lead to the best overall outcome in all ... cases, but Nash's Trap (which is now called the Nash Equilibrium) draws us by the logic of our own self-interest into a situation in which at least one of the parties fares worse but from which they can't escape without faring worse still. That is why it is such an effective trap. If we are to learn to cooperate more effectively, we need to find ways to avoid or escape from the trap.

Fisher 2008, i-ii.

The Nash equilibrium illustrates a basic principal of game theory. Anatol Rapoport (Rapoport 1960) came up with a simple negotiation formula to avoid the Nash trap by offering cooperation on the first move and thereafter doing exactly what the other side does. Reward cooperation with cooperation and defection with defection. He called this 'Tit for Tat'. This approach has been further expanded by game theorists (Fader and Hauser 1988) who called their strategy Implicit Cooperation. They suggested that it often pays to be more cooperative in multi person situations and that magnanimity and forgiveness are key factors in promoting cooperation in the presence of someone who is not cooperating.

Mediators face parties caught in a Nash trap every time they mediate. It leads to the classic mediator verbal intervention: "As I look around the room I cannot see any winners here. Everyone here is a loser in some form". Often the trap revolves around the ever-increasing legal costs and who is going to be liable for them; a classic example of the Nash Equilibrium at play.

International examples of where equilibrium has been reached include the nuclear arms race during the Cold War, the Catholics and Protestants in Northern Ireland, the Israelis and the Palestinians, the Sunnis and the Shi'ites and the gun control/gun violence issue in the United States.

It is clear from research into game theory that the only way out of the trap is through some form of cooperation, magnanimity and forgiveness. The earlier this takes place the quicker is the escape from the Nash trap. The power of gift giving by way of making concessions is the first step towards engendering cooperation (Mauss 1990, Rooney and Ross 2012). The nuclear arms race, the Northern Ireland troubles and apartheid South Africa resolved through negotiation facilitated by the granting of concessions as the path to building cooperation and trust. 


\section{The Rise of the Collaborative Economy}

The collaborative economy is described as:

An economy built on distributed networks of connected individuals and communities versus centralised institutions, transforming how we can produce, consume, finance and learn.

Botsman, 2013

There are three distinguishing features:

1. There is a platform that connects individuals and groups directly with each other. It can be the internet or through traditional networking associations.

2. That the platform reduces transaction costs. These include search and information costs, bargaining and decision costs and policy and enforcement costs. The legal profession and the courts system are transaction costs.

3. There is an inbuilt self-correcting system built on peer reviews. This allows for a rating system and an opportunity to deal with complaints and disputes immediately.

The collaborative economy is driven by low transaction costs. This has a marked effect on the role of intermediaries such as lawyers. The traditional black letter contract creating rights and obligations with sanctions supported by the litigation system is obsolete in this context. In much the same way it challenges the legislature as over regulation can nullify the economic benefits.

This new economy will also impact on dispute resolution processes. Online reviews and social media create a transparent method of identifying problems and resolving them. The aim is to create a trust relationship between the parties as the basis of the contractual arrangement. This transparent rating and feedback system is an instant self-enforcing strategy that is an inbuilt counter to the Nash trap (Fisher 2008). Establishing and maintaining trust is essential in the commercial sense because the time at the top for new businesses is increasingly limited in the digital age.

The provision of early term relationship based mediation is the most constructive way for the legal profession to engage with this new economy. The profession will have to adapt both in terms of developing contractual agreements built on trust as well as providing relationship based and trust building dispute resolution services.

\section{The Role of Pre-action ADR Initiatives}

The pre-litigation ADR initiatives introduced by the legislature in Australia have played an important part in the development of early intervention mediation processes especially in commercial disputes. It has forced lawyers to engage in a genuine discussion with their clients at a very early stage in the litigation cycle about the option of using collaborative processes. This, in tandem with the evolving collaborative commercial environment has helped the growth of mediation in Australia.

The certification requirements of the Civil Dispute Resolution Act and the lesser requirements of the various State Acts have had a direct impact on the professional duty and responsibility of lawyers. 
This is reinforced by the cost implications for the lawyers and their clients of the failure to take the required 'genuine steps'.

At a policy level the introduction of pre-action protocols is recognition that litigation should be considered by the legal profession as a process of last resort. It encourages the use of mediation and allied ADR processes to help short-circuit the parties when sinking ever deeper into a lose/lose Nash Equilibrium.

\section{The Challenge for the Judiciary and the Legal Profession in the $21^{\text {st }}$ century}

The challenge for the mediation profession and allied ADR practitioners, the legal profession and the judiciary is to find their proper place within the dispute and conflict resolution framework as we move further into the $21^{\text {st }}$ century.

\section{The Judiciary}

For the judiciary the challenge is to adjust to the fact that it is no longer the principal means of resolving disputes in the commercial framework. Mediation as a process has challenged that assumption.

The judiciary has traditionally referred to access to the courts as access to Justice. It is as if the concept of Justice is synonymous with the courts. This raises the question as to whether adjudicating on the facts of a particular case ipso facto amounts to Justice.

The observations of his Honour Mr Justice P. W. Young (retired) of the New South Wales Court of Appeal are particularly relevant:

Just as judges do not make law, they do not resolve disputes, rather, they adjudicate upon them.

Young 2002, 213.

Can justice only be dispensed by the judiciary?

Just as health is not found primarily in hospitals or knowledge in schools, so Justice is not primarily to found in official Justice-dispensing institutions. Ultimately, access to Justice is not just a matter of bringing cases to a font of official Justice, but of enhancing the justice quality of the relations and transactions in which people are engaged.

Galanter 1981, Sourdin November 2012, 893

Justice must also be looked at in the context of compromise. The giving up of a just and legally enforceable right to obtain the benefits of a release from the Nash trap challenges the concept of justice.

Justice, like the concepts of neutrality, equality and balanced power, is a theoretical construct that does not exist outside of theory. It is a subjective term which is at most an aspiration, the degree of attainment of which can only be assessed after the determination has occurred (subject to appeal). Therefore, justice can only be assessed in retrospect.

In a negotiated settlement, whether through direct negotiations or mediation, justice is in the hands of the parties and can be assessed by them before the agreement is reached. The only test is whether, in all the circumstances, the results of the agreement were good enough. Justice can reside in 
such an agreement even though just rights and entitlements are abandoned or compromised (Rooney 2015).

\section{The Legal Profession}

The challenge for the legal profession is whether it retains its traditional role as a trusted profession always acting in the best interests of its clients or whether it continues its current drift towards a commercial profit based service industry as has been the trend in Australia over the last 15 years.

This change began when the legislature deregulated scale legal fees in the 1980s with a view of putting downward pressure on legal fees. The opposite occurred. Legal fees escalated for much the same reason that corporate senior executives' remuneration packages have escalated. The higher the charge or remuneration package the better the quality of the lawyer or the corporate executive is presumed to be. No lawyer or senior executive would like to be seen as cheap compared to their rivals. The result of this move from competition between quality of service to competition on price was that the profession has driven the cost of legal services much higher than the market value of the service it provides.

How then does the law as it is currently practised fit with the concept that the clients' best escape from the Nash trap is to settle early through compromise. Perhaps some advice from Abraham Lincoln extolling the lawyer's role as peacemaker might be of assistance.

Discourage litigation. Persuade your neighbours to compromise whenever you can. Point out to them how the nominal winner is often a real loser-in fees, expenses, and waste of time. As a peacemaker, the lawyer has a superior opportunity of being a good man. There will still be a business enough. Lincoln 1850

The risk of diminished professional legal fees is not far removed from the core problem facing the legal profession by the changed commercial landscape and the rise of mediation.

\section{The Clients and Potential Clients}

Clients no longer unquestioningly place their trust and welfare in the hands of professionals (Dr Google is kept very busy). They are more informed and discerning than previous generations. They want their lawyers to provide realistic and creative options for dealing with disputes. They prefer options that create opportunities and minimise the risk of involvement in further disputes (Rooney 2002).

Examples such as Project Allianceing in the oil and gas and construction industries where parties enter into a relationship contract expressly excluding litigation (Rooney 2009) and the Australian version of Dispute Boards that have a pre-dispute issues focus are examples of creative commercial contracts that allow conflict to be dealt with in-house well before they escalate into a dispute. Conflict can also be seen as a business opportunity and as a vehicle for making constructive changes as per the philosophy behind the concept of Dispute System Design (Ury et al 1988, Costantino et al 1996).

Mathematician Len Fisher calls these 'self-enforcing strategies' which he states carry their own enforcement so that there is no incentive to cheat on cooperation once it has been established. It is a 
creative and pro-active antidote to the Nash trap.

An opportunity exists for enterprising lawyers and other professionals to develop these relationship building processes and the agreements that flow from them. These challenging economic times call for more flexible relationship-based contractual arrangements based on shared pain and gain. This is a challenge to traditional contractual agreements in which owners seek to transfer all risks to contracting parties. These are inherently unstable contractual arrangements and inevitably lead to litigation and costs blow outs for the project.

In recent years a considerable number of projects have not been for your works...these cut prices are illusionary, especially as a contractor who is working at a loss is like a drowning man who clutches at straw. In the case of the contractor this means he does not pay his suppliers, cheats everyone he can, underpays his men, getting the worst, not only using the most inferior materials, but quibbling over everything and always begging forgiveness over this and that. Abandon [this type of competitive tendering] Re-establish good faith, give the estimation of the work and not refuse a reasonable payment to a contractor who will fulfil his obligations. That will always be the best transaction you will be able to find. (Marshal Vauban, (1633 - 1707), Chief of Fortifications for Louis XIV - a letter from Sébastien Le Prestre de Vauban, Maréchal de France written $17^{\text {th }}$ July 1685 from the island Belle-Isle-en-Mer (Bretagne) to Louvois, Superintendent of Buildings of France). Vauban 1685, Green 1991, Construction Queensland, 2001, 8

The recent rise of the collaborative is underpinned by the direct link between risk- taking and innovation. They are essential ingredients for maintaining the increasingly short time at the top in the 21st Century economy.

It is through the ability of management and external advisors to creatively manage the tension created by risk-taking that best fosters a culture of trust and innovation.

If lawyers do not adjust their adversarial culture and develop the soft skills necessary to meet these challenges organisations will find people with degrees in dispute resolution, business, commerce, psychology and engineering that will (Rooney 2002).

\section{The Legislators}

Part of the motivation to introduce pre-litigation ADR requirements is cost efficiency. However, there are more fundamental reasons to do with good governance, commercial harmony and economic growth.

Economic advantage can be gained by legislating processes that allow commercial organisations to resolve disputes in an efficient and timely manner. As an example, Great Britain became a great maritime trading nation overtaking the Italian maritime republics of Genoa, Venice and Amalfi principally because the British Admiralty laws and Admiralty Courts offered a far superior and simpler system for resolving maritime disputes than the complex maritime laws of the Italian city states. $21^{\text {st }}$ century Russian 
oligarchs use the British Justice system for the same reason.

\section{Mediators}

The major benefit to mediators through the introduction of the Civil Dispute Resolution Act and other similar acts in Australia is that the legislature requires lawyers to consider mediation almost at the time of taking instructions.

This creates an opportunity for mediators although there are still significant challenges to overcome.

The main marketing challenges are:

a. How do mediators market themselves, particularly in the early stages of a dispute, to a sceptical legal profession that likes to keep control over access to their clients?

b. What is the product we are trying to sell? Unless we are clear about what we provide to the parties, their lawyers and to the general dispute resolution system we will continue to have difficulties selling the product.

C. Mediators are promoted as being third party neutrals. Neutrality is therefore at the core of our brand recognition. Yet neutrality is a theoretical construct

that does not exist outside of theory. This is at the core of our confused self-identity and the reason why it is hard to market our product. Until the mediation profession sorts this out it will continue to be substrata of the law and the social sciences and will be seen through theirlenses.

The main practice challenges are:

a. How mediators can get access to the parties and their lawyers at the earliest stages of the litigation cycle. Getting our foot in the door. Part of the solution is to promote the value of the pre-mediation meetings by expanding the definition of mediation to include a pre-mediation conference with each party and their lawyer

b. The value to the process and outcome of the mediator assisting in the facilitation of discovery. Mediators do not have any power to order discovery but they can assist in facilitating it. This is one of the greatest challenges for mediators as lawyers are often unwilling to bring in a mediator until after discovery has been completed.

C. Introducing soft skills into the negotiating process at this early stage. The art of influencing the parties is achieved by avoiding any talk about the parties' hard positions, possible outcomes and the law. It is at the level of the non- contentious pre-mediation administrative functions that mediators see parties with their guards down. It is through these exchanges that the parties reveal their true underlying needs and desires. It is a chance for the mediator to engage a deeper level. 


\section{Marketing the Mediation Product Lawyers are the Consumer}

People, especially in the commercial arena, still traditionally go to lawyers as a first port of call where there is a dispute. Lawyers undertake a triage role in deciding which product they will use to resolve the conflict; whether it is direct negotiation with the other lawyer, mediation, arbitration, collaborative engagement or litigation. So lawyers are in effect the consumer.

The mediation product is difficult to sell partly because it is still trying to work out what it is. This is not uncommon for a new profession struggling to come out of the shadow of traditional source professions such as the law and the social sciences. Although there are different models and philosophical approaches the traditional answer seems to be that the mediator is a third party neutral.

So we market ourselves as neutral. There are two problems with this. The first is that we are not neutral and the second is that the word neutrality can also mean apathy (Rooney 2015, 5). We are trying to sell something akin to apathy.

\section{The Problem with Neutrality - It Doesn't Exist}

Neutrality is physically and emotionally impossible to attain as a personal attribute for a mediator. The same applies to the concepts of 'just outcomes' and 'balanced power'. They are all theoretical constructs which do not exist outside of theory.

There is nothing theorists can point to that would indicate to a mediator when these states have been physically achieved. They are subjective concepts subject to infinite variables especially in the context of the fluid art of compromise. They are at most aspirations the degree of success of which can only be assessed after the event has occurred.

Neutrality, just outcomes and balanced power are states that can only be assessed in retrospect. This leaves mediators with the situation that they cannot predict the true status of their neutrality, issues of justice in the outcome and power differentials. They have to wait until they and the parties have undergone the experience to judge what has occurred. Having experienced the experience there is no formal benchmark with which to judge whether those states were achieved. The only valid assessment can be whether, in all the circumstances, the results of the process and outcome were good enough.

There are good reasons to detach from the concept of mediator neutrality as the basis of mediator behaviour. It is counter-productive because it programs mediators' minds into accepting a state that is unattainable. It distorts how mediators view themselves as practitioners as well as how they see themselves relating to the parties. Paradoxically it installs an internal program in their minds that can unintentionally mask their own hidden prejudices, biases and preconditioning (Rooney 2015).

\section{Beyond Neutrality}

Bernard Mayer in his book 'Beyond Neutrality' (Mayer 2004) advocates moving away from mediator neutrality mainly to add value to the mediation product and for marketing reasons.

But it goes deeper than just marketing. We can never really be a legitimate profession until we 
can understand and explain what we are doing in the mediation session and why we are doing it. The third party neutral explanation is not an answer because it is an illusion.

The mediator is not a distant or bland observer having no effect on the moment to moment exchanges in the mediation session as the concept of neutrality suggests. Both the mediator and the parties (and their lawyers) are equal co-creators of each moment in the mediation just by their physical presence. How mediators think affects how they behave. Everything we do has an effect. Until we can answer the question of 'what do we do and why do we do it 'we will continue to struggle to sell ourselves as a stand-alone profession. So the mediation profession has to get its own house in order.

\section{The Main Practice Challenges Promoting the Pre-Mediation Meeting}

In my view the pre-mediation meeting with the parties and their attorneys is one of the biggest contributors to the success or otherwise of a mediation. It has far more impact and offers a far greater source of personal connection with the parties than the private meeting or caucus held during the mediation session. The new pre-action litigation legislation opens the door for more use of this valuable part of the mediation process.

There is some debate as to whether a pre-mediation meeting is separate to or part of the mediation process. I would argue that the definition of mediation should include a compulsory premediation meeting. This would bring the mediator's experience and professionalism into the requirement for lawyers and their clients to consider private prevention and resolution processes before referring the dispute to the courts as per the Code of Civil Procedure in Québec and making genuine steps as per the Civil Dispute Resolution Act in Australia.

The early entry of the mediator can also be of assistance in facilitating discovery. The longer the mediator works with the parties before they start the hard negotiation the more the mediator can build a personal relationship with them and their lawyers.

\section{Promoting the Soft skills of the Mediator}

Parties are influenced by legal issues and the opinion and advice of their lawyers when considering settlement. However, the actual decision to compromise and to say "yes" and settle is taken by the parties at the personal level on the emotional relationship plane. That emotional relationship connection between the mediator and the parties has to be kept intact right from the initial meeting right through to the final "yes I will settle". The earlier the mediator can establish that relationship the more it can be nurtured.

It is by working through non-contentious administrative and discovery issues that the mediator can build such a relationship. It is much harder to do this in a private session during the mediation when parties are at their most defensive.

The tools for such work are to be found in the soft mediation skills particularly the ability to remain present in the moment, intuition, empathy, rapport, managing the challenge of being an irritant 
and the use of time and space (Temporality, 'The Third', 'The Field') and Meditation/Mindfulness (Rooney and Ross 2012).

The pre-action requirements open the door for mediators to build an early relationship with the parties. It then becomes a marketing issue to show value in their involvement so early in the process. To do this mediator must show that they are something more than just third party neutrals and that they bring a discrete set of skills and expertise that can add value to the process and the outcome.

\section{Conclusion}

There are a number of reasons why the legislature has sought to impose pre- litigation protocols on the legal profession and the parties. It would be simplistic to say it is just revenue driven and to dismiss them by adopting a minimalist response hoping that they will go away.

Historically self-regulation is a first step and precursor to a more interventionist regulatory approach by the legislature, especially where self-regulation is seen to be ineffective. Therefore, failure by the judiciary, legal profession and to some extent by mediators and other allied ADR professionals to take up this challenge set by the pre-action ADR requirements can eventually lead to a more interventionist approach by the legislature.

The legislated pre-litigation ADR initiatives are designed to pressure lawyers into mediating much earlier in the litigation cycle. This requires a different mediation style, one that is relationship based and facilitative with more of a focus on the soft skills of the mediator.

Part of the motivation for earlier mediation is cost efficiency, but at a more fundamental level, it is a reflection of the fact that we are living in changing times especially in the commercial world. There is far more fluidity and unpredictability in commercial activity as we progress into the $21^{\text {st }}$ century.

We live in a fast changing commercial world driven by internet connectivity and cross border commercial activity. The Internet and social media are driving this change with challenges to established industries such as Uber with the taxi industry, Airbnb with the hotel industry, Twitter with the political establishment and the traditional news media, YouTube with the advertising industry, Google with all of the professions particularly medicine, on line shopping with the retail industry, renewables with the energy industry, robotics with the manufacturing industry and so on.

These $21^{\text {st }}$-century commercial platforms challenge to traditional industries and professions are being referred to as the "collaborative economy or the disruptive economy" (Ransom 2016). Mediation's challenge to adversarial litigation can be seen in much the same way.

This high level of interconnectedness, both personal and commercial, creates significant levels of relationship complexity which adds a significant layer of uncertainty and unpredictability to any commercial enterprise. How people relate to each other and their ability to communicate and resolve differences are crucial to the proper functioning of this modern complex society. The emphasis by business on managerial 'soft skills' is evidence of this.

The greatest challenge for the modern legal system and lawyers is the speed at which these 
changes are occurring. We are witnessing the effects of exponential commercial change - change that increases by multiples of itself. For example, Uber grew from a zero base in mid-2012 to be a $\$ 50$ billion company today. It is this speed of change together with the relationship complexity of modern commercial activity that will have the most adverse impact on the slow, adversarial and expensive traditional judicial approach to resolving conflict.

Mediation and other ADR practices will therefore have to play a far greater role, perhaps even a dominant role, for the commercial lawyer and business leader, in the $21^{\text {st }}$ century.

Early relationship-based mediation can be the pathway for commercial lawyers and the $19^{\text {th }}$ century judicial processes to move into and play a respected part in the new $21^{\text {st }}$ century collaborative commercial economy. 


\section{References}

Civil Dispute Resolution Act $2011 \quad$ (Cth) No. 17, 2011 https://www.comlaw.gov.au/Details/C2011A00017

Bergin P.A. (2007) Mediation in Hong Kong: The way forward. Perspectives from Australia presented at the Hong Kong international arbitration centre $30 \quad$ November 2007 http://www.supremecourt.justice.nsw.gov.au/Documents/bergin301107.pdf Botsman, R. (2013), "The Sharing economy Lacks a Shared Definition", available at: http://www.fastcoexist.com/3022028/the-sharingeconomy-lacks-a-shared- definition\#4

Costantino, C.A. Sickles Merchant, C. (1996) Designing Conflict Management Systems Jossey-Bass

Construction Queensland. (2001) Wealth Creation through Equitable Asset Delivery

- Final Report and Implementation Guide, a report to the Queensland Government dated March 2001.

De Jersey P. (2002) Has mediation eclipsed litigation, and is the statutory minefield still work negotiating-and by the way, what's happening with the common law. http://archive.sclqld.org.au/judgepub/2002/dj310502.pdf Fader, P.S. \& Hauser, J.R.(1988) Implicit Coalitions in a Generalized Prisoner's Dilemma Journal of Conflict Resolution September 1988 32:553-582,

Fisher, L. (2008) Rock, Paper, Scissors - Game Theory in Everyday Life. Basic Books, New York.

Galanter, M. (1981) Justice in Many Rooms" in Mauro Cappelletti (ed), Access to Justice and the Welfare State (Sijthoff and Noordhoff, 1981) 147, 161-2.

Green R, Macdonald D, Mitchell W and Mitchell C (1991) 'Rise and Fall and Cost Reimbursement Clauses', Department of Industrial Relations Research Series No 1, April, DIR, Canberra.

Lincoln, A. (1850) I Am Not an Accomplished Lawyer cited in Abraham Lincoln's notes for a law lecturer. www.showcase.netine.net/web/creative/lincoln/speeches/lawlect.htm

Mauss, M. (1990) The Gift: The Form and Reason for Exchange in Archaic Societies

New York W.W. Norton \& Company

Mayer, B.S. (2004) Beyond Neutrality, Confronting the Crisis in Conflict Resolution, San Francisco: Jossey-Bass Publications.

NADRAC (2009). The Resolve to Resolve-Embracing ADR to Improve Access to Justice in the Federal Jurisdiction https://www.ag.gov.au/LegalSystem/AlternateDisputeResolution/Documents/NAD RAC\%20Publications/the-resolve-to-resolve-embracing-adr-improve-access-to- $\quad$ justiceseptember2009.pdf

NADRAC (2011 Maintaining and enhancing the integrity of ADR processes. The principles to practice through people https://www.ag.gov.au/LegalSystem/AlternateDisputeResolution/Documents/NAD

RAC\%20Publications/Maintaining\%20and\%20enhancing $\% 20$ the $\% 20$ integrity $\% 20$ of $\% 20 \mathrm{~A}$

DR\%20processes\%20\%20From\%20principles\%20to\%20practice\%20through\%20people.P DF

Ogden, T. H. (2015) Intuiting the Truth of What's Happening : On Bion's "Notes on Memory and Desire. The Psychoanalytic Quarterly, 2015, Volume LXXXIV, Number 2 Ransom, H. (2016) http://www.theaustralian.com.au/national-affairs/young-to- drive-economy-overhaul/story-fn59niix1227569426683 ? sv $=9 \mathrm{~d} 503 \mathrm{f} 2295 \mathrm{e} 274369 \mathrm{bf} 3 \mathrm{e} 49 \mathrm{df} 37 \mathrm{~d} 04 \mathrm{eb}$ 
Rapoport, A. (1960) Fights, Games and Debates, Ann Arbor, MI: University of Michigan Press.

Rooney, G. (2002) Mediation and the Rise of Relationship Contracting - A Decade of Change for lawyers- Law Society of South Australian Bulletin, Volume 24, Number 7, August 2002- Law Institute Journal Victoria, Volume 76, Number 10 , November 2002 -Proctor, Queensland Law Journal, Volume 22, Number 6, July 2002

Rooney, G. (2009) Project Alliancing-Applying Advanced Conflict Management Systems to Complex Infrastructure Projects. Available at SSRN: http://ssrn.com/abstract=1809267

Rooney, G. and Ross, M. (2012) Shifting the Focus from Mediating the Problem to Mediating the Moment - Using Intuition as a Guide (September 1, 2012). Available at SSRN: http://ssrn.com/abstract=2140220

Spanish Translation: - Rooney, G. and Ross, M. (2014) Un cambio de foco: de mediar el problema a mediar el momento. Uso de la intuición como guía", Revista de Mediación 2014, vol. 7, No. 1, pp. 36-46

Rooney, G. (2015) Rebooting Mediation by Detacbing from the Illusions of Neutrality, Just Outcomes and Balanced Power (February 12, 2015). Available at SSRN: http://ssrn.com/abstract=2564035

Russian Translation: Rooney, G. (2016) Perezagruzka mediatsii//Mediatsia i Pravo Mediation and Law. Intermediation and Conciliation, Moscow ,1 (39), 2016, pp. 50-

69.

Slattery, M. J. QC. (1993) The Spedley Mediation from the Inside

New South Wales

Bar News. 1993 Ed 27

Sourdin, T, (2009) Mediation in the Supreme and County Courts of Victoria (April 1, 2009). Report prepared for the Department of Justice, Victoria, Australia, April 2009.

http://www.civiljustice.info/cgi/viewcontent.cgi?article=1000\&context=adreval Sourdin, T. (March

Resolving Disputes without Courts Measuring the Impact of Civil Pre-action

Obligations Background Paper, March 2012 http://www.monash.edu/ data/assets/pdf_file/0020/140933/acji-pre-action- background-paper-mar2012.pdf

Sourdin, T. (October 2012) Exploring Civil Pre-Action Requirements: Resolving Disputes Outside Courts. Australian Centre for Justice Innovation Civil Justice

$\begin{array}{lllll}\text { Research Online } & \text { ACJI, } & \text { Monash } & \text { University, } & \text { October }\end{array}$ http://www.civiljustice.info/cgi/viewcontent.cgi?article=1025\&context=access Sourdin, T. (November 2012) Civil Dispute Resolution Obligations: What Is Reasonable? UNSW Law Journal volume 35 (3) http:/ / wnw.unswlawjournal.unsw.edu.au/sites/all/ themes/unsw/images/Tania-Sourdin.pdf

Ury, W.L. Brett, J.M. and Goldberg, S.B. (1988) Getting Disputes Resolved Jossey- Bass

Vauban, Marshal (1685) Chief of Fortifications for Louis XIV - a letter from Sébastien Le Prestre de Vauban, Maréchal de France written $17^{\text {th }}$ July 1685 from the island Belle-Isle-en-Mer (Bretagne) to Louvois (Superintendent of Buildings of France) Archives nationales de Paris. PUBLIÉ PAR WWW. TSB-

INFORMATIQUE. COM À L'ADRESSE 19: 08

Young, P.W. (2002) ADR: A Generic, Holistic Concept, 76 ALJ 213 at 213. 


\section{A version of this paper was first presented at the 6th Symposium of the Institut de médiation et d'arbitrage du Québec in Montréal on the 4 November 2015.}

Greg Rooney has been a practising mediator in Australia for 24 years. His professional background is in the law. Greg specialises in mediating disputes in the early stages of the litigation cycle. He has completed more than 1,500 mediations in a wide area of disputes and 1,200 mediations/arbitrations in the NSW Workers Compensation jurisdiction. He has, since 1995, taught mediation and ADR subjects at a number of Australian universities and private institutions www.gregrooney.com.au

Greg together with colleagues Margaret Ross and Barbara Wilson run, annually, a Mediation Retreat in Tuscany, Italy, based on the theme: "Moving the Focus from Mediating the Problem to Mediating the Moment". http://tuscanymediation.com.au/ 